\title{
Bilateral congenital ocular defects in a foal
}

\author{
A. GARNER AND P. GRIFFITHS
}

Department of Pathology, Institute of Ophthalmology, University of London; and Burton-on-Trent, Staffordshire

The purpose of this paper is to describe congenital defects, having no direct counterpart in the literature, that affected both eyes of a new-born foal of pedigree racing stock, which otherwise appeared to be entirely healthy as were both the sire and the dam.

\section{Pathological findings}

RIGHT EYE

Macroscopical examination

The contents of the orbit consisted of a much shrunken eye embedded in fat (Fig. I). The opened globe was found to be severely disorganized and there was complete retinal detachment.

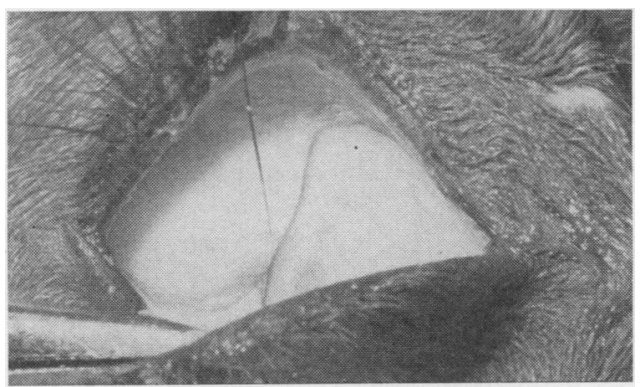

FIG. I Right eye. The contents of the orbit are shrunken and partially covered by "nictitating membrane"

\section{Microscopical examination}

Sections, cut in a vertical plane to include the nictitating membrane (Fig. 2), showed that the anterior surface of this structure was composed of tissue bearing a marked resemblance to skin in that the

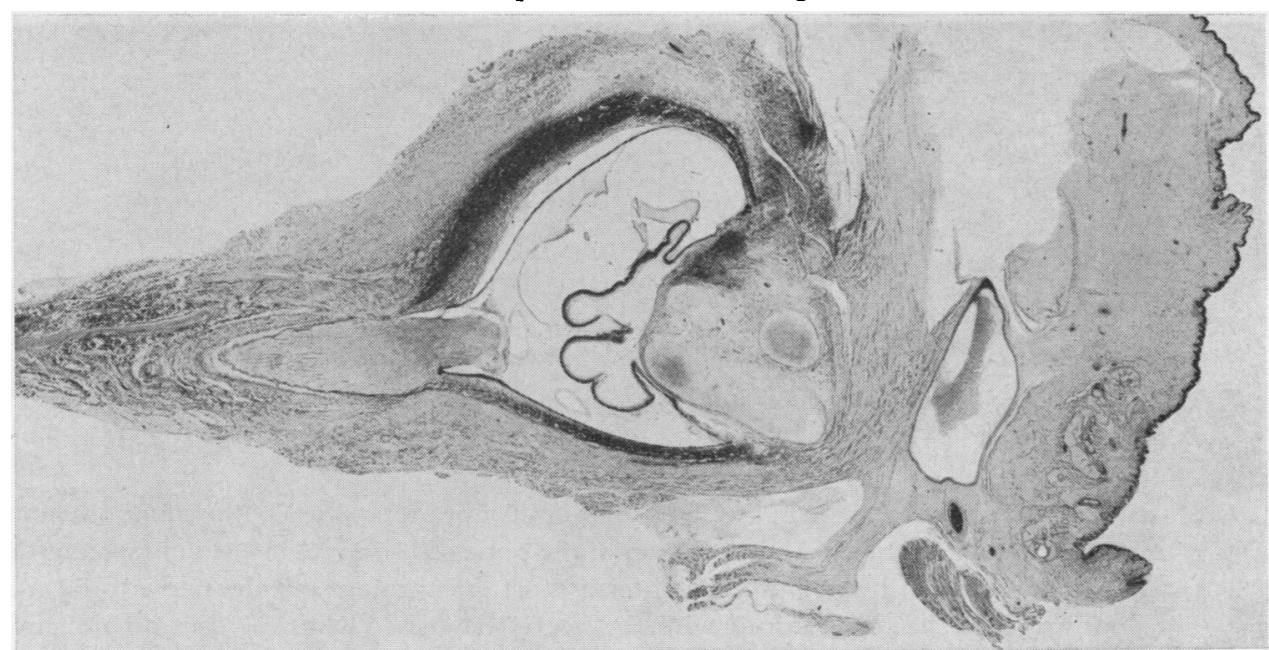

FIG. 2 Right eye. Section cut in vertical plane shows, from right to left, nictitating membrane, conjunctival sac, pseudocornea, nodules of cartilage embedded in mesenchyme, detached retina, and colobomatous defect of the optic nerve entrance. Haematoxylin and eosin. $\quad \times 6$ 
epithelium was of squamous cell (though non-keratinizing) type and that dermal appendages were present in the superficial stroma; the stroma also showed mild round cell infiltration. The deep aspect of the membrane was lined by typical conjunctival epithelium. There was no structure recognizable as cornea, its place being occupied by mature fibrous tissue continuous with the anterior $\stackrel{\vec{\Omega}}{\overrightarrow{2}}$ sclera, lined in front by conjunctival epithelium continuous with and similar to that lining the back of the nictitating membrane (Fig. 3), and posteriorly merging with a mass of loose mesenchyme showing. several circumscribed foci of differentiation into hyaline cartilage. There was total absence of the

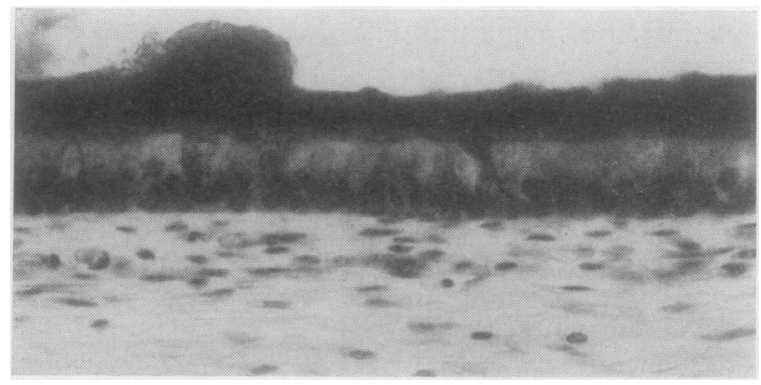

FIG. 3 Right eye. Anterior surface of pseudocornea lined by transitional cell and mucin-secreting epithelium. Periodic acidSchiff. $\times 300$

anterior chamber, iris, ciliary body, and lens, which were replaced by this immature and metaplasticc్ connective tissue. The retina was completely detached and thrown into folds, and showed a poorlydeveloped nerve fibre layer, while at the periphery there was some dysplasia in the form of rosettes and $\vec{\varnothing}$ incomplete organization (Fig. 4); the subretinal space contained an eosinophilic exudate.

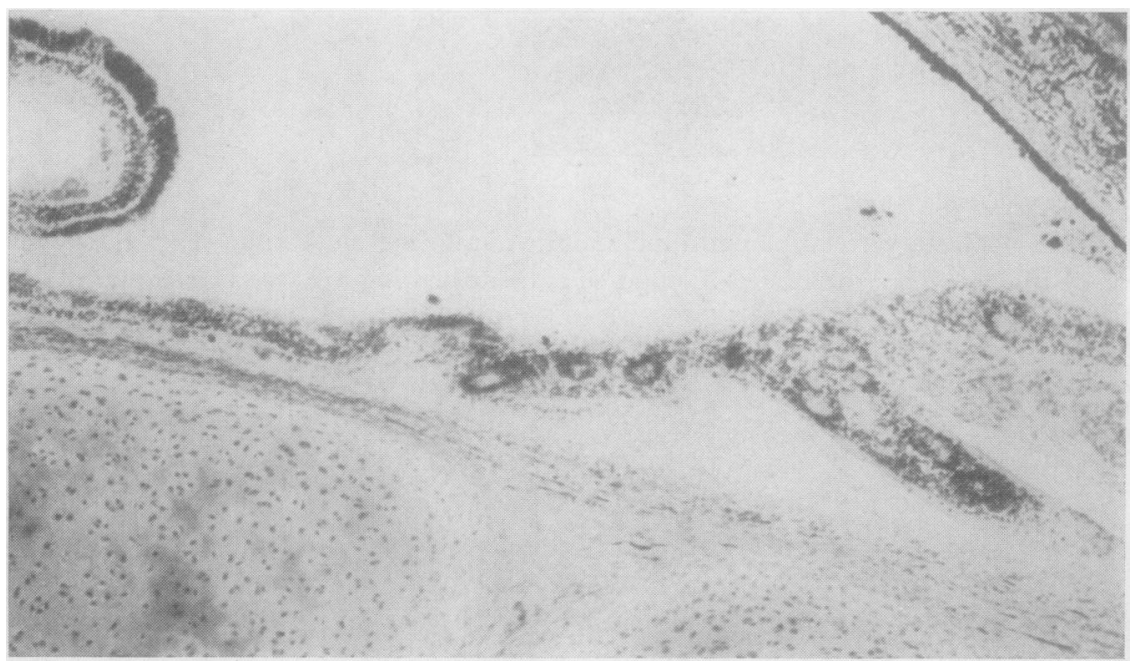

FIG. 4 Right eye. Peripheral retina in proximity to the cartilaginous mesenchyme of the anterior segment is dysplastic with the formation of rosettes. Haematoxylin and eosin. $\times 60$

No abnormality was seen in the choroid or in the fibrous tapetum of the superior hemisphere. The $\frac{0}{\bar{D}}$ sclera also was normal save in the region of the optic disc, where, instead of forming the usual sieve- $\stackrel{\mathbb{N}}{\mathscr{N}}$ like lamina cribrosa, it was prolonged for a short distance around the nerve to form a loose fitting collar which posteriorly merged with the nerve sheath. There was thus a coloboma of the optic nerve entrance lined by choroidal tissue. The nerve itself was somewhat hypoplastic and the nerve $\stackrel{\mathbb{D}}{\Omega}$ head was drawn forward as a result of the retinal detachment and the lack of a lamina cribrosa to act $\underset{\Omega}{\mathbb{Q}}$ as an anchor. 


\section{LEFT EYE}

\section{Macroscopical examination}

The eye was of about normal size but showed a rounded anterior staphyloma (Fig. 5); the lens appeared to be subluxated in an upward direction and had an irregular surface; the retina was detached.

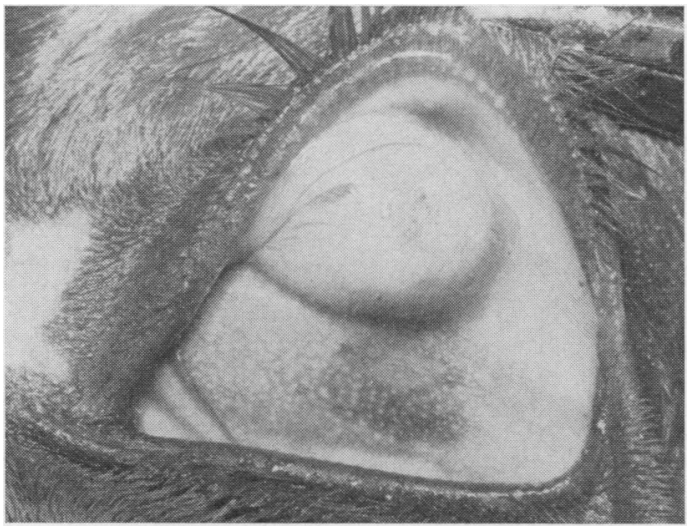

FIG. 5 Left eye. The globe shows an anterior staphyloma with epidermalization and pigmentation of the inferior bulbar conjunctiva

\section{Microscopical examination}

Anteriorly there was a large staphyloma involving the expected position of the cornea (Fig. 6), although there was no proper differentiation of the cornea in so far as Bowman's and Descemet's membranes were absent and the squamous epithelium covering the staphyloma resembled that of skin, being thrown into folds with well-marked rete peg formation but without keratinization of the surface layers. Deep to the epithelium was a zone of loose vascularized connective tissue infiltrated with moderate numbers of round cells, while deeper still there was a wide band of mature fibrous tissue enclosing within its layers a zone of primitive mesenchyme arranged in whorls and containing a solitary focus of cartilage. Except for the region in the immediate vicinity of the cartilaginous

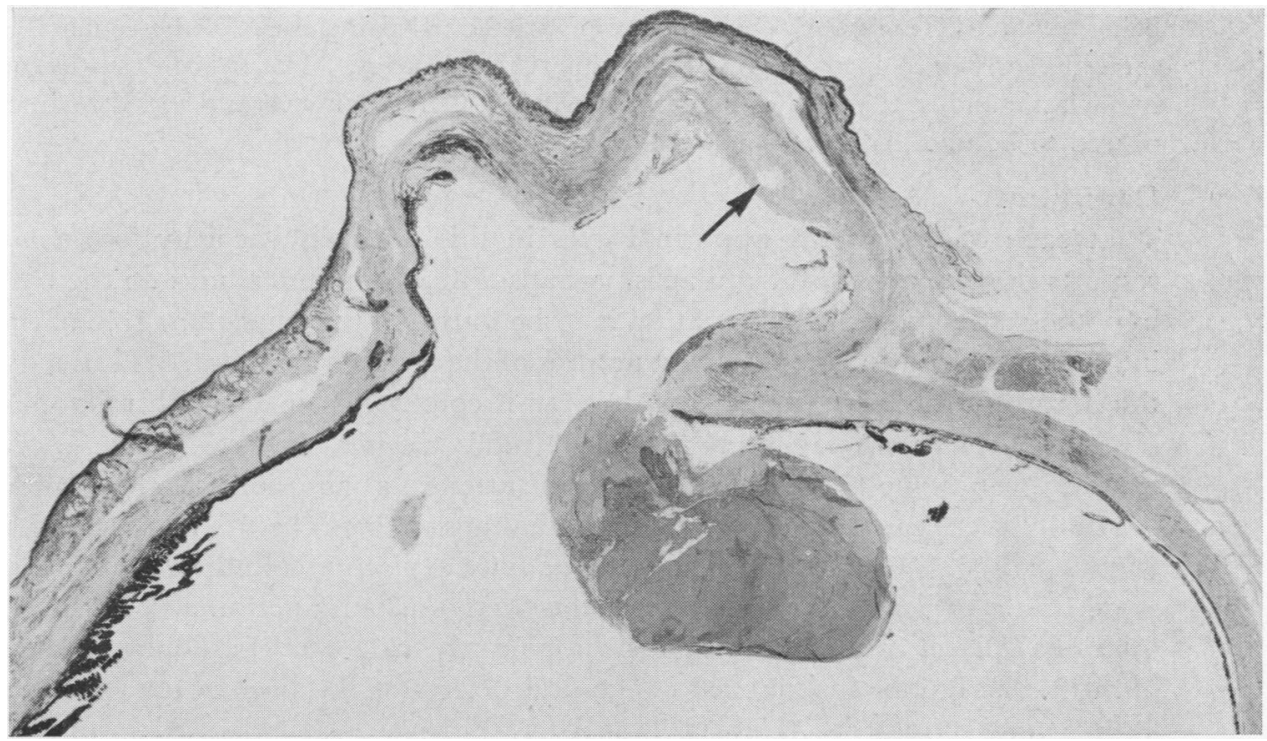

FIG. 6 Left eye. Section through the anterior staphyloma showing a nodule of cartilage (arrow) in its deeper layers and epidermalization of the surface epithelium. Haematoxylin and eosin. $\times 6$ 
nodule the internal surface of the staphyloma was lined by ciliary epithelium partially embedded in mesenchyme and showing pseudo-adenomatous hyperplasia (Fig. 7). More mature ciliary body tissue with well-developed processes was present in the non-staphylomatous part of the anterior segment. The superior bulbar conjunctiva was essentially normal but inferiorly it was replaced by skin which included hair follicles and numerous sebaceous glands; peripherally this zone of dermal metaplasia reverted to a more normal type of conjunctival tissue. The lens was subluxated slightly, was cataractous, and showed a partially deficient capsule.

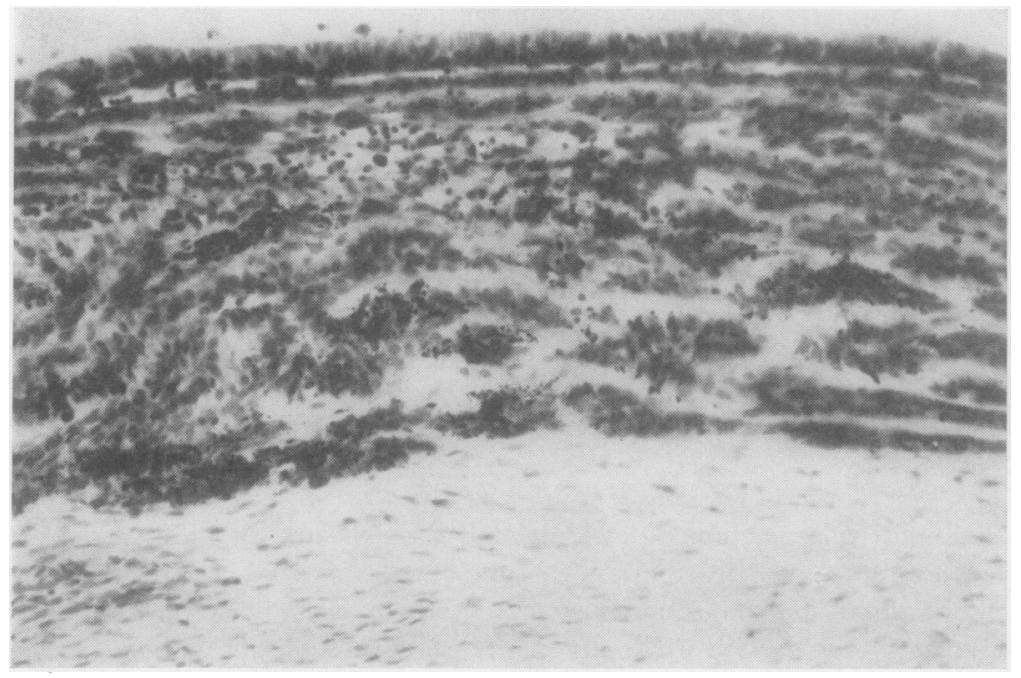

FIG. 7 Left eye. Pseudoadenomatous hyperplasia of ciliary epithelium embedded within the loose connective tissue lining the proximal parts of the staphyloma. Haematoxylin and eosin. 35

The posterior part of the globe was much less abnormal, the choroid, fibrous tapetum, and sclera being apparently normal. There was some artefactual detachment of the retina which otherwise showed poorly-developed ganglion cell and nerve fibre layers. The optic nerve was correspondingly? hypoplastic and at the level of the lamina cribrosa there were several whorled nodules of what ap-응. peared to be undifferentiated mesenchyme.

\section{Comment}

That each of the grossly abnormal eyes in this otherwise healthy foal should in many respects be so markedly dissimilar is perhaps difficult to understand on the basis of a single 0 hypothesis. A possible explanation is to be found in the important role of the lens in the induction and maturation of the structures of the anterior segment. Thus a disturbance in the maturation of the lens placode in man is commonly linked with microphthalmos and No absence of the anterior chamber (Becker, I888; Fischer, 1934) whereas, once the lens has $N$ formed, even though it be incomplete, some attempt at anterior chamber and iris formationN్ is usually seen and there is no microphthalmos (Wagenmann, I889; von Hippel, I906; 0 Mehta, 1947). These differing situations may explain our findings in the foal, wherein aco single insult affecting the right eye at the time of lens induction and affecting the left eye fractionally later could account for the apparently widely diverse abnormalities. Disparity? between the lesions in bilateral congenital defects of the human eye is of course not unknown and it may be relevant that Duke-Elder (1964) refers to instances of anterior staphyloma with abortive anterior chamber formation in the presence of the lens in one eye $\frac{\vec{\Phi}}{\mathscr{Q}}$ and microphthalmos on the other side. 
The pathogenesis of the disturbance is uncertain but it is quite possible that the bilateral and abnormal differentiation of the mesenchyme lying between the optic vesicle and the surface ectoderm into cartilage is in some way implicated. Mesodermal metaplasia is occasionally seen in this region in human congenital defects and, though as a rule differentiation is usually directed towards a fibro-fatty type of growth, it may, as in the foal's right eye, proliferate unduly to form a fairly prominent mass (Mann, I930). It would, therefore, appear that in both cases the nature of the defects depends on whether metaplasia develops before or after the induction of the lens. The finding of cartilage is interesting for another reason, for Cogan and Kuwabara (1964) and Keith (1966) found it to be a characteristic and possibly pathognomonic feature of the human $13^{-1} 5$ trisomy syndrome. Unfortunately the chromosomal status of the present case is not known and, despite the absence of obvious defects in other organs, it is not possible to exclude the existence of a comparable type of anomaly without a complete necropsy.

That the front of the nictitating membrane of the right eye should be covered by "skin" rather than conjunctiva would seem to reflect a failure of differentiation on the part of the surface ectoderm. The peripherally placed retinal dysplasia seen in this eye closely resembles the replacement of the non-pigmented epithelium of the pars plana by dysplastic retina with rosettes reported in human cases (Coats, I9o9; Fuchs, 1917). None of the colobomata of the human optic nerve entrance appears to conform precisely with that seen here, but perhaps the closest is that described by Pedler ( $196 I)$ in which he considered the basic defect to be a failure of maturation of the posterior sclera.

Mayou (1932) described bilateral ocular defects in a foal which in one eye partially resembled those in the left eye of the present animal : in particular, he found acinarstructures in the cornea similar to those in the staphyloma of our case, but whereas he interpreted them as derivatives of Harderian gland we believe them to be due to a pseudoadenomatous hyperplasia of the ciliary epithelium.

\section{Summary}

Bilateral congenital defects in a foal are described. While the eyes were in many respects dissimilar, one showing an anterior staphyloma and the other a microphthalmos, they shared a tendency to form cartilage and it is suggested that this mesodermal metaplasia lay at the root of the subsequent anomalous developments.

We are indebted to Prof. Norman Ashton for advice and helpful criticism, to Mr. V. Ellwood for technical assistance, and Miss A. Martyn for secretarial work.

\section{References}

BECKer, H. (1888) v. Graefes Arch. Ophthal., 34, pt 3, 103

coATs, G. (1909) Ophthalmoscope, 7, 724

COGAN, D. G., and KUWABARA, T. (1964) Arch. Ophthal. (Chicago), 72, 246

DUKE-ELDER, s. (1964) "System of Ophthalmology", vol. 3, pt 2, p. 524. Kimpton, London

Fischer, F. (1934) v. Graefes Arch. Ophthal., 132, 71

FUCHS, E. (1917) Ibid., 93, I

HIPPEL, E. VON (1908) Ibid., 68, 354

KEITH, c. G. (1966) Trans. ophthal. Soc. U.K., 86, 435

MANN, I. (1930) Brit. F. Ophthal., 14, 32 I

MAYOU, M. s. (1932) Trans. ophthal. Soc. U.K., 52, 57

MEHTA, к. (1947) Brit. med. F., 1, 68 I

PEDLER, C. (1961) Brit. 7. Ophthal., 45, 803

wagenmann, A. (1889) v. Graejes Arch. Ophthal., 35, pt 3, i I I 